Kensington Museum. That phenomena so diverse in their origin and appearance should be mistaken for each other does not say too much in favour of the cultivation of the observational faculties of artists as a rule.

I shall next refer to two or three other questions which have been dealt with by Prof. Brücke in the article to which I have referred. Prof. Brücke is again with me to a certain extent in tracing the origin of most skycolour to a defect of the blue light, but he does not make the attempt to run it to earth that I have done, by ascribing it to aqueous vapour ; indeed he considers it rather due, I take it, to the presence of solid particles in the air. Thus, after pointing out that the dawn is generally orange, and the sunset redder, he states that at night the quantity of molecules capable of troubling the air is generally greater. For my own part, I should be inclined to ask whether, during the night, the molecules of aqueous vapour which absorb the blue have not been driven into higher forms--dew being one of them-owing to the reduction of temperature. This would at once explain not only the generic difference between sunrise and sunset colours, which is more marked here than in the tropics; but also the golden instead of red sunsets which accompany the formation of cloud.

Another point of difference. Prof. Brücke considers green sky as an effect of contrast produced by the quantity of red light which enters the eye. I cannot agree to this, first, because I bave given a physical reason for the green; and secondly, because I have observed it without any strong contrast of colour to mislead the eye. The considerable darkening of the green after sunset is, I believe, purely physiological; and it is an effect of so curious a nature, that it raises several interesting questions with regard to the manner in which the eye grapples with the middle colours of the spectrum, namely, the orange, yellow, and green, which can be made to change to a certain extent according as the light is more or less intense, which does not happen with the other colours.

The changes in mountain scenery form the subject of several interesting remarks by Prof. Briicke. As long as distant mountains are illuminated by a high sun, their outlines are not very clear; because, as he well puts it, the reflection of this light from the lower strata of the atmosphere is then so great that the illumination at the horizon, where mountains are, is as strong as where they are not. He then points out that at night the setting sun fills the s'zy towards the west with a great brightness which renders the profiles of the mountains between us and the sun much darker. Their contours are neatly detached, but it is not only on the horizon that this is seen; the various chains are better distinguished, and appear one behind the other like the scenes in a theatre, because the light in which we see them does not come from them but from the interposed air. The sides of the mountains which we see are dark because the other sides are turned towards the sun, but the various thicknesses of air interposed between us and them reflect to us the sunlight; hence the atmosphere of a picture is truly the work of the air.

Here is what Prof. Briicke says about sunset tints ; I do not follow him in all his explanations:- "When the sun reaches the horizon and the red tint is developed, the colours of the landscape change in their turn and the mountains themselves appear red when we regard no longer their. shadows but the illuminated air which lies in front of them." It appears to me this gives too much work to the air; a rock surface is generally as capable of dispersing red light which falls upon it, as a molecule of aqueous vapour is; "still the tint has not the intensity of the alpine colour; it is a red less intense and more empurpled, which sometimes approaches even the violet or the lilac."

I shall have a word to say on this, but I will first give Prof. Brücke's explanation :-
"Two causes are at work in this latter case; the first is the mixture of red and blue light. At night when the sky is clear the shadows are coloured a strong blue. The shadow region is illuminated by the blue light of the sky, and appears more pronounced, owing to the contrast of the reddish-yellow light, as we have already seen. The illuminated air reflects the blue rays more abundantly than the red ones, and consequently the former have the ascendency. If not scientifically correct, it is at least practically so, to suppose the blue light in which we see the mountains bathed after sunset to be mixed with purple or lilac. The second cause of the violet tone in the distances to the west is to be found in the frequent contrast. : In the west, in fact, a great part of the sky is illuminated by yellow light; often this yellow is a perfect sulphurcolour, which contrast makes objects even in the middle distance, which turn their dark sides to us, appear violet; thus, looking to the west, dark, unploughed earth appears violet when the majority of terrestrial objects turn their dark sides towards us."

An observation I made at Cannes last year leads me to think that the whole cause of this purple colour has not been stated in the foregoing. It was near the hour of sunset, and I was looking towards the southwest, delighting in the blue colour at the foot of Les Estrelles-while their crests were being gilded by the sunset-when, almost instantaneously, the valley to the north of these hills was enfiladed by a beam from the sun itself, which threw part of the aqueous vapour in the valley into a frenzy of gold. This gradually got ruddier as the sun got lower, and the amount of vapour lighted up between me and the blue vapour at the foot of the hills was at the same time reduced; the blue and the red then melted together into the richest and most beautiful purple that I, at all events, have ever seen.

We have only, then, to assume that, when we thus see purple, that colour is produced by a mixture of particles, some of which are reflecting to us the blue light of the sky, because they can do no other, while others, again, are reflecting to us the red light of sunset, because it is more powerful than the light from the sky.

J. NORMAN LOCKYER

\section{AN ECLIPSE SPECTROSCOPE}

SOME little time ago I communicated to the Royal Socicty a suggestion for the use of Mr. Rutherfurd's reflection gratings in obtaining photographs of the coming eclipse. The plan suggested was that the grating should be placed short of the focal point of a telescope, and at right angles to its axis, and that the diffracted images of the chromosphere should be received on photographic plates adjusted for the different orders of spectra on either side the axis. I am glad to learn from Prof. Newcomb that the value of this method of observation will probably be tested by Prof. Young, who is in charge of one of the six expeditions already organised to observe the eclipse. The chief defect in this mode of observation lies in the difficulty of determining the position of the lines photographed, supposing the chromospheric spectrum to vary considerably from the ordinary solar one so far as the intensity of the lines is concerned; and as it seemed desirable that these gratings should be utilised for less serious attacks, I have recently been endeavouring to see if the method can be improved.

The annexed woodcut shows one form of the new arrangement, which has many conveniences. It is a rough model on wood, but will suffice to show the method of use.

The grating, which is free to rotate, is placed in front of a little telescope of low magnifying power and the stand which carries both is so placed and the grating so 
adjusted that the image of the light source is seen in the little telescope reflected by the general surface of the metal grating. Supposing a circle and micrometer attached, represented by the wooden bar at the top, the reading would now be zero.

Next, and this is the new point, a piece of glass silvered on the front surface is fixed with its surface parallel to the surface of the grating, the side of which it covers. When this is in perfect adjustment the images produced by the movable grating and the fixed mirror are superposed. Let us suppose the light source to be a Geissler tube, we get a single image of it ; the fixed mirror is then very slightly inclined, so that its image lies a little above or below the one due to the grating. We now by the movable arm at top rotate the grating, the grating image vanishes from the field of view, and in a little time, if the rotation is continued, the blue of the first order spectrum makes its appearance. Each coloured image in the spectrum can in turn be brought to coincidence, with the nondispersed image of the tube thrown by the fixed mirror, and readings of considerable accuracy can thus be obtained. The illumination of the image due to the

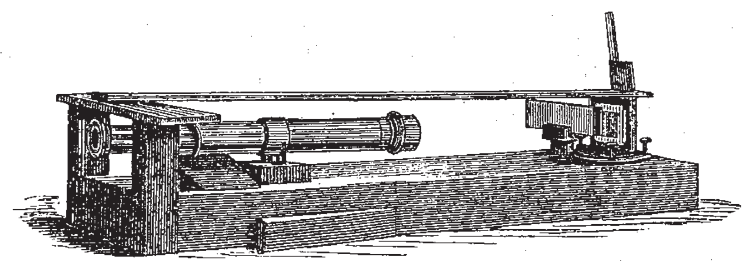

fixed mirror can be easily regulated by changing its position with regard to the axis of the telescope prolonged; in no case of course should any part of the ruled surface of the grating be covered. With a ring slit illuminated by the vapours of different metals, the phenomena observed are very interesting and novel; with the fixed mirror slightly inclined, the image from the fixed mirror always in the centre of the field of view forms a capital point of comparison.

More light is gained by employing an object-glass of short focus and placing the grating and fixed mirror at such a distance inside the focus that the beam falls on the ruled surface and a small fraction of the fixed mirror.

I hope the suggestion does not come too late to enable it to be utilised by the outposts during the coming eclipse. If it helps in enabling us to determine the position of the chromospheric line near $H$, the time I have spent on the little model will not have been thrown away. I may add that I have found that a prism of $60^{\circ}$ dense flint placed in front of the lens of an ordinary photographic camera will give us, if properly focussed, a most useful spectrum of the eclipsed sun.

J. NORMAN LOCKYER

\section{OUR ASTRONOMICAL COLUMN}

NeAREst Approximations of SMall Planets to THE EARTH'S ORBIT.-Out of the 187 minor planets now known there are ten which approach the earth's orbit at their perihelia within $0^{\circ} 9$ of her mean distance from the sun, and which may therefore afford the most advantageous opportunities for determination of the solar parallax by one or other method of observation of these bodies, already successfully applied: Medusa is omitted on account of uncertainty of elements. The nearest approach, $0^{\circ} 798$, is made by Clio, discovered by Luther in August, r 865 . AEthra, detected by Watson in June, I873, makes the nearest approach to the sun $I^{\cdot} 6$ I 4 ; but the great depression of the planet below the plane of the ecliptic, at perihelion, prevents so near an approximation to the earth's orbit as in the case of Clio. The following is a tabular view of the distances in the ten cases referred to :-

\begin{tabular}{|c|c|c|c|c|c|c|c|c|}
\hline . & & & & $\begin{array}{l}\text { Perihelion } \\
\text { Distance. }\end{array}$ & & $\begin{array}{l}\text { Heliocentric } \\
\text { Latitude } \\
\text { in Perihelion. }\end{array}$ & & $\begin{array}{l}\text { Distance } \\
\text { from } \\
\text { Carth's Orbit. }\end{array}$ \\
\hline 84. & Clio & & & $1 \cdot 805$ & $\cdots$ & $\begin{array}{r}\circ \\
+\quad 157\end{array}$ & $\cdots$ & 0.798 \\
\hline 132. & Ethra ... & $\ldots$ & $\ldots$ & $I \cdot 6 I 4$ & $\ldots$ & -2345 & $\ldots$ & 0.813 \\
\hline I8. & Melpomene & e... & $\ldots$ & I.796 & $\ldots$ & -79 & $\ldots$ & 0.815 \\
\hline 43. & Ariadne & $\ldots$ & $\ldots$ & $I \cdot 834$ & $\ldots$ & +048 & $\ldots$ & 0.818 \\
\hline 12. & Victoria & $\ldots$ & $\ldots$ & $1 \cdot 823$ & $\ldots$ & $\begin{array}{r}740 \\
+\quad 740\end{array}$ & $\ldots$ & 0.828 \\
\hline 80. & Sappho & $\ldots$ & $\ldots$ & $I \cdot 835$ & $\ldots$ & $\begin{array}{r}5 \\
+\quad 553\end{array}$ & $\ldots$ & 0.842 \\
\hline 8. & Flora ... & $\ldots$ & $\ldots$ & I.856 & ... & -545 & $\ldots$ & 0.874 \\
\hline 33. & Polyhymnia & & ... & $1 \cdot 890$ & $\ldots$ & -053 & $\ldots$ & $0.88 i$ \\
\hline 42 . & Isis & $\ldots$ & ... & I'890 & $\ldots$ & -653 & $\ldots$ & 0.892 \\
\hline 50. & Virginia & $\cdots$ & & $I \cdot 896$ & $\ldots$ & $-\quad 047$ & $\ldots$ & 0.896 \\
\hline
\end{tabular}

If we extended our limit to $I^{\circ} \circ$ we should include, in addition to the above, Felicitas, Phocea, Euterpe; Thyra, Echo, and Feronia.

While referring to the small planets it may be remarked that, between the perihelion of Ethra and the aphelion of Hilda, there is a difference of 2.98 ; and between the aphelion of Flora and the perihelion of Hilda $0^{\circ} 76$, or upwards of three-fourths of the radius of the earth's orbit. The periods of Flora and Hilda being respectively 3.27 and 7.85 years exhibit a difference of 4.58 years. These are the extremes, as they result. from the latest and most complete catalogue of elements.

According to the last Circular of the Berliner Jahrbuch, the following names bave been proposed:-For No. 177, Irma, for 180, Garumna, and for 186, Celuta.

MeAsures of Double Stars.-Many applications for copies of the earlier volumes of "the Leyton Observations" having been received after the edition had been exhausted, Mr. J. Gurney Barclay has issued a fourth volume containing the double star epochs from the commencement of observations at Leyton, with the addition of results to the end of 1877 . This part includes also occultations and phenomena of Jupiter's satellites since I865. The notes on the double-star observations comprise the principal epochs of other observers. The small companion of Procyon at a distance of about forty-five seconds, to which attention was first pointedly directed by Mr. Barclay in January, I 856, had the following posi-

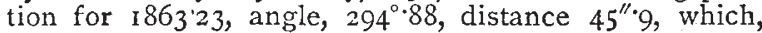
corrected for the proper motion of Procyon in the interval, gives for $1879^{\circ} 0$ angle, $319^{\circ} 3$, distance $47^{\prime \prime} \cdot 3$.

The Astronomische Nachrichten, Nos. 2196-99, contain measures of double-stars made by Dr. Doberck at the observatory of Col. Cooper,'Markree Castle, Sligo, from the end of 1875 to the spring of 1878 . The list includes most of the well-known binary systems. $\gamma$ Coronæ was single in the Markree instrument in $1876-77$.

Mr. Ormond Stone, Director of the Observatory at Cincinnati, writes with respect to a remark in a notice of the Cincinnati measures of double-stars, which appeared in this column, and which might be misunderstood as implying that the work carried on at the American Observatory is to a certain extent a duplication of that commenced some time since with the refractor at Melbourne. Mr. Ellery, however, has lately informed Mr. Ormond Stone that his observations are limited to stars south of $35^{\circ}$.

The Binary Star $a$ CentaurI.-Mr. Maxwell Hall writes from Jamaica, on May 21 , with reference to a Centauri : "Since my communication last year respecting this binary, the angle of position of the smaller star has rapidly increased at the rate of $60^{\circ}$ per annum. I have lately taken measures in the same manner as before, few in number, but with the greatest care, so that their concordance gives them great weight."

Epoch $18788^{\circ} 8$ Position $139^{\circ} \cdot \mathrm{I}$ Distance $2^{\prime \prime} \% 4$

Mr. Hall adds: "There can be no doubt that the smaller star is variable: according to my estimates it has diminished during the last year; and I would therefore call attention to the subject"-and appends-various estimates from $\mathrm{I} \frac{1}{2}$ (Powell, Jacob) to 4 (Dunlop), also a table of the measured angles and distances to 1878 , which it is 